\title{
PSYCHE
}

\begin{tabular}{lll}
\hline Vol. 96 & 1989 & No. 1-2 \\
\hline
\end{tabular}

\section{THE "BOUNCER" DEFENSE OF ODONTOMACHUS RUGINODIS AND OTHER ODONTOMACHINE ANTS (HYMENOPTERA: FORMICIDAE)}

\author{
By Norman F. Carlin ${ }^{1}$ ANd David S. Gladstein ${ }^{2}$
}

\section{INTRODUCTION}

The genera Odontomachus and Anochetus constitute the ponerine tribe Odontomachini ${ }^{3}$, one of three unrelated ant tribes-the others being the formicine Myrmoteratini and the myrmicine Dacetini-which have convergently evolved a remarkable "trap jaw" mechanism (Creighton 1930). All odontomachines and myrmoteratines, and many dacetines, possess conspicuously elongate, linear mandibles which can close with a convulsive snap, catching prey between pointed apical teeth. Primarily a predatory adaptation, the trap jaws have been secondarily employed in defense against other ants by at least one dacetine species (Carlin 1981). This paper reports evidence that Odontomachus ruginodis and other odontomachine ants have convergently applied their mandibular strike to a secondary defensive function.

The narrowly inserted mandibles of trap-jawed ants are held parallel when closed, but can be opened to about $180^{\circ}$ in Odontomachus (Fig. 1) and up to $280^{\circ}$ in Myrmoteras (Moffett 1986). Hypertrophied mandible adductor muscles expand the occipital region, resulting in a variety of peculiar head shapes (Wheeler 1927). Most, but not all, trap-jawed species also possess one or two pairs of prominent, long sensory hairs which point forward when the mandibles are held fully open (Fig. 1, bottom). Stimulating these so-called

'Museum of Comparative Zoology Laboratories, Harvard University, Cambridge, MA 02138

2ICAD, Inc., 1000 Massachusetts Ave., Cambridge, MA 02138

${ }^{3}$ Though Brown (1976) reduced this group to a subtribe of the Ponerini, this paper follows Hölldobler and Wilson (in press) in retaining the tribal rank.

Manuscript received by the editor February 16, 1989. 

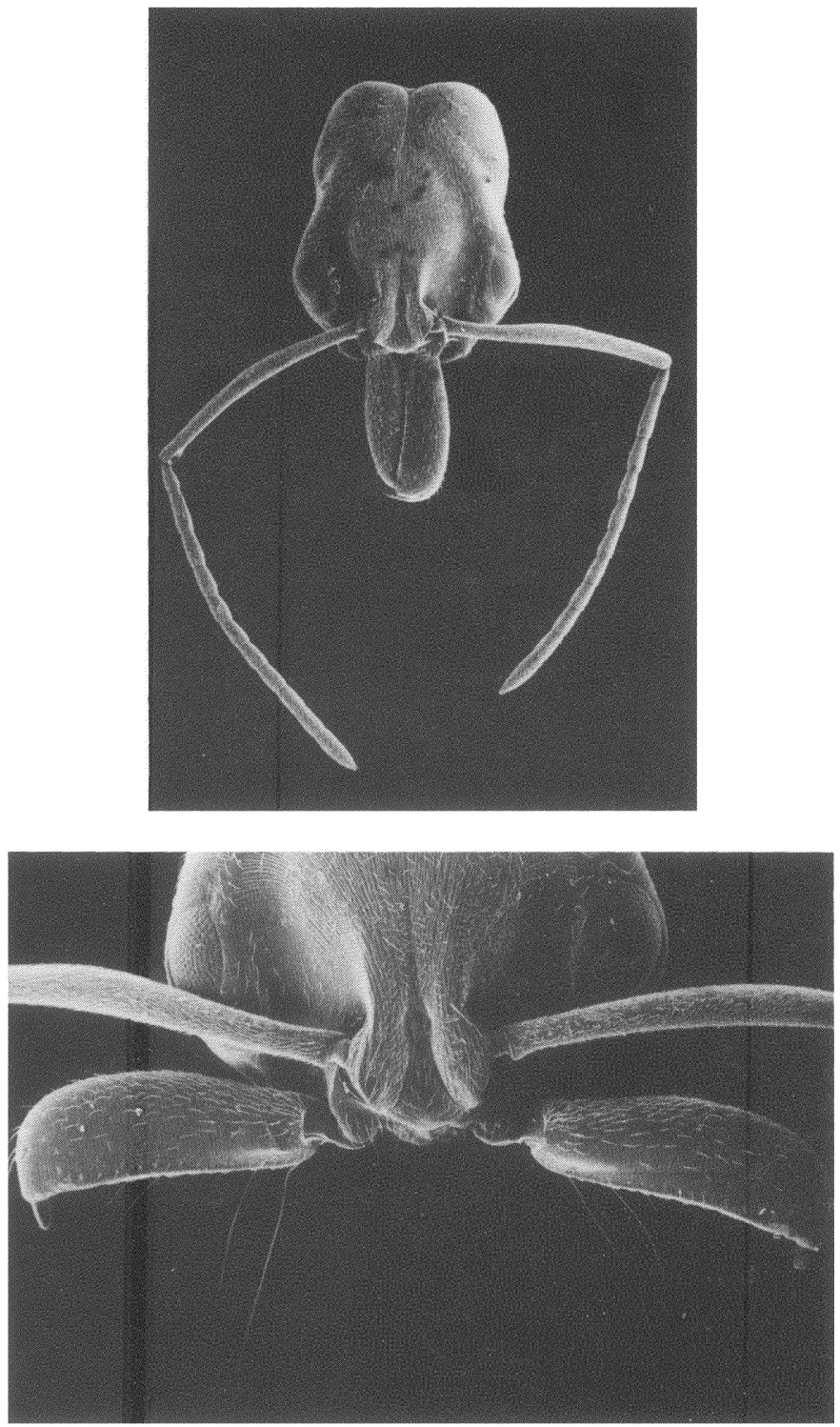

Fig. 1. Top: Head of an $O$. ruginodis worker, mandibles closed. Bottom: Close-up view of opened mandibles; note trigger hairs extending forward. 
trigger hairs releases closure of the mandibles, accompanied in larger species by an audible click. The hairs, which originate near the bases of the mandibles in the Odontomachini, and from the labrum in the Myrmoteratini and Dacetini, are just long enough that an object which contacts them is struck by the apical teeth (Creighton 1930). The functional morphology of the odontomachine trap-jaw mechanism has been elucidated by Barth (1960). When the mandibles are opened wide, stiff tendons bend, storing energy like springs, while the mandibles' basal condyles slip into notches in their sockets which hold them open without muscular tension. Contraction of the large adductor muscles pops the mandibles free of the restraining notches and, with tendon springs released, they snap abruptly shut.

Trap-jawed species are solitary huntresses, using the mandibular strike to impale or injure soft-bodied arthropods (Ledoux 1952, Brown and Wilson 1959, Wilson 1962, Fowler 1980, Dejean and Bashingwa 1985, Dejean 1986, Moffett 1986). Brown (1976) suggested that the elongated mandibles and quick strike-and-recoil behavior of odontomachines may reduce risk when attacking chemically well-protected prey such as termites, while myrmoteratines and trap-jawed dacetines are noted for capturing elusive collembola (Brown and Wilson 1959, Moffett 1986). However, majors of the Australian dacetine Orectognathus versicolor, which have massive mandibles bearing blunt and recessed apical teeth, contribute little to prey capture. Instead, they spend much of their time standing in the nest opening with mandibles cocked. Any alien ant that intrudes will be struck by one of these guards, the apical mandibular teeth pinching the intruder's sclerotized extremity with sufficient force to propel it backward through the air for several centimeters. This "bouncer" defense effectively ejects aliens and reduces the risk of physical or chemical injury to the guard.

Having noted Odontomachus ruginodis workers in southern Florida stationed in nest entrances in the same posture (Fig. 2), we conducted field and laboratory experiments on this species' guarding behavior and responses to intruders. A few other odontomachine species that became available in the laboratory during these studies were also observed. In addition, we tested a queueing theory model to determine whether $O$. ruginodis guards randomly succeed one another in the nest opening, and investigated the sensory stimuli 


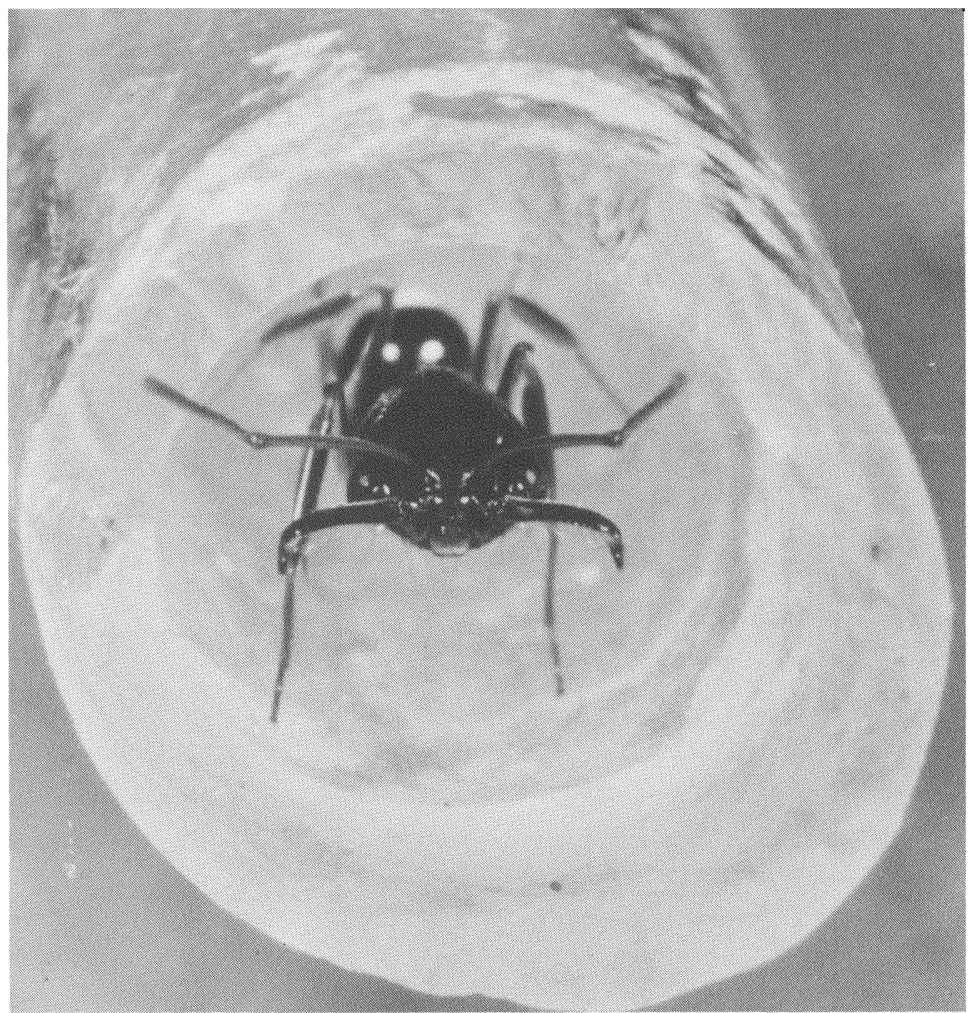

Fig. 2. O. ruginodis worker in the guarding posture, in the glass entrance tube of a laboratory nest.

that elicit the mandibular strike in $O$. bauri, which is larger than $O$. ruginodis and more easily subjected to manipulation. The discussion compares our results with available information on the use of trap jaws in defense by other ants.

\section{Materials AND Methods}

$O$. ruginodis colonies were observed in the field and collected on the Saddlebunch Keys, Monroe Co., Florida. (See Deyrup et al. (1985) for differentiation of the three Odontomachus species occurring in Florida.) Voucher specimens were deposited in the Museum of Comparative Zoology, Harvard University, and the collection of 
the Archbold Biological Station, Lake Placid, Florida. In the laboratory, the ants were housed in glass test tubes $(2.2 \mathrm{~cm}$ diameter $\times 15$ $\mathrm{cm})$, containing water trapped at the end behind a cotton plug. Each tube was sealed with a plastic cap, pierced with a glass entrance tube (4 mm inner diameter) through which foragers could emerge, and placed in an open plastic arena $(19.5 \times 14 \times 7.5 \mathrm{~cm})$, with sides coated with Fluon to prevent escape. Ant diet (Bhatkar and Whitcomb 1970) and chopped beetle larvae (Tenebrio) or frozen flies (Drosophila) were provided in the arena twice weekly. Chopped cockroach nymphs (Nauphoeta), ant larvae (Camponotus) and termite workers (Nasutitermes and Reticulitermes) were also offered on occasion.

All workers in two colonies were individually marked with spots of colored paint on thorax and gaster. One colony contained a queen, 15 workers, 13 larvae and 8 eggs, and the other, which had recently lost its queen when observations began, contained 19 workers, 1 pupa, 1 larva and 3 eggs. The identity and behavior of ants standing in the entrance tubes were recorded during 12 one-hour sessions over a period of 13 days. Three sessions per colony were conducted during the day and three at night, under red light. Defensive responses to alien ants were tested by sliding a vial containing an intruder onto the end of the entrance tube while a guard was present, or by placing Odontomachus workers and aliens in a plaster-floored dish $(9 \mathrm{~cm}$ diameter) or empty plastic arena $(19.5 \times$ $14 \mathrm{~cm})$. Interactions in both contexts were recorded on videotape.

Additional observations were made on several other odontomachines: $O$. bauri collected in Santurce, Puerto Rico by C. Garcia and on Barro Colorado Island, Panama by S. Pratt, O. bauri and Anochetus emarginatus collected in Manzalli, Trinidad by M. Fujita, $O$. brunneus collected in Leon Co., Florida by N. F. Carlin and P. Calabi, and $O$. clarus collected in Bexar Co., Texas by D. Wheeler. Sensory mechanisms involved in the mandibular strike were tested in a series of ablation experiments using $O$. bauri. Workers whose trigger hairs and/or one or both antennal funiculi were removed by razor blade, and/or whose eyes were covered with opaque yellow paint, were introduced to alien ants in a plaster-floored dish and recorded on videotape. 


\section{ResUlts}

\section{Field observations}

In 1982 and 1983, O. ruginodis was found in moderate abundance along roadsides in the lower Florida Keys, nesting in the dry, stony soil under moisture-retaining objects such as logs or pieces of cardboard. (More recent collecting suggests that the species may have become less common in this habitat, perhaps due to efforts to clean up roadside trash.) Colonies contained one queen and up to about 50 workers each. Nests were shallow and diffuse, consisting of several small chambers among which adults and brood were scattered, without an obvious central chamber or single brood pile. Most nests had multiple narrow, debris-filled entrances from which only one ant could emerge at a time. Solitary workers foraged on the ground and on mangroves, frequently with their mandibles cocked in open position. Workers recruited to dilute honey baits, though no trails were observed; the return of a successful forager apparently stimulated others to emerge from the nest and search nearby in an undirected manner. When nests were excavated, the ants exhibited alarm recruitment, releasing alkylpyrazine alarm pheromones (Wheeler and Blum 1973) and stridulating, both of which are detectable to humans.

Often a disturbed worker, rushing about with open mandibles, contacted a large object such as a stone (or the observer), snapped the mandibles against it, and flew backward for a distance of several centimeters. This jumping or "retrosalience" behavior, which has been frequently reported in a variety of trap-jawed species, was interpreted as an escape response in the older literature (e.g., Wassmann 1892, Wheeler 1900, 1922). However, Creighton (1930) and Weyer (1930) suggested that the jumps occur accidentally, when alarmed ants whose mandibles are set to strike blunder into hard obstacles. Our observations support the latter view, since $O$. ruginodis workers which had just "escaped" by this means almost always rushed immediately back to the area from which they had been displaced, rather than fleeing, and frequently struck the same object again.

Workers standing motionless for extended periods, with open mandibles, were frequently observed in one or more of the entrances of undisturbed nests. The role of these putative guards was investigated using fire ant (Solenopsis invicta) workers collected from a 
Table 1. Episodes of nest entrance guarding recorded in 12 hours' observation of one queenright and one queenless colony of $O$. ruginodis. Time given in minutes; percent of coverage $=$ percentage of total observation time during which a guard was present at the entrance. The single individuals in each colony that guarded most frequently were considered to be "specialists". $N=$ number of individuals. See text for details.

\begin{tabular}{lccc}
\hline & $\begin{array}{c}\text { Number } \\
\text { of acts }\end{array}$ & $\begin{array}{c}\text { Time and percent } \\
\text { of coverage }\end{array}$ & $\begin{array}{c}\text { Duration } \\
\text { of acts }\end{array}$ \\
\hline Total & 72 & $272(38 \%)$ & $3.8 \pm 4.7$ \\
Day $\quad(\mathrm{N}=32)$ & 53 & $195.5(54 \%)$ & $3.7 \pm 4.0$ \\
Night & $19 \mathrm{a}^{\mathrm{a}}$ & $76.5(21 \%)$ & $4.0 \pm 6.4$ \\
Queenright $(\mathrm{N}=13)$ & 37 & $162.5(45 \%)$ & $4.4 \pm 5.8$ \\
Queenless $(\mathrm{N}=19)$ & 35 & $109.5(30 \%)$ & $3.1 \pm 3.2$ \\
“Specialists" $(\mathrm{N}=2)$ & 17 & $100(14 \%)$ & $5.9 \pm 6.6$ \\
Others $(\mathrm{N}=30)$ & 55 & $172(24 \%)$ & $3.1 \pm 3.9$ \\
\hline
\end{tabular}

${ }^{\mathrm{a}} \mathrm{p}<0.05$, binomial test

b not significant $(\mathrm{p}>0.05)$, binomial test

${ }^{c}$ not significant $(\mathrm{p}>0.05), \mathrm{t}$ test

colony on Key West. It proved impossible to introduce single intruders, as fire ants placed at a nest entrance simply walked away; when one was confined in a glass vial abutting the opening, the inhabitants became excited (either by volatile secretions from the fire ant or by the physical disturbance of the entrance) and rushed out. Instead, it was necessary to adopt the somewhat cruder expedient of dumping about 200 fire ant workers directly atop a nest. When the first $S$. invicta worker entered an opening, the guard struck and propelled it backward for several centimeters. After 1-3 fire ants had been ejected in this manner, and others had gone into unguarded entrances, most of the workers in the nest excitedly emerged and began snapping at the fire ants, dismembering some and shooting others away. This sequence of bouncing of initial invaders, followed by alarm recruitment as the invasion progressed, was observed in five field colonies.

Nest guarding in laboratory colonies

$O$. ruginodis workers in the laboratory were frequently observed standing for prolonged periods in the entrance tube, facing outward with mandibles cocked and antennae extended (Fig. 2). Individuals 
generally stationed themselves just at the opening when assuming the guarding posture. After remaining motionless in this position for a time, the worker either backed slowly into the nest, while keeping its mandibles open, or was pushed out from behind by the next guard. On occasion a guard emerged spontaneously and moved out into the arena. Guards usually crouched to allow nestmates to climb over them, though sometimes they prevented others from entering or exiting. Queens never came to nest entrances. In a limited series of observations, newly-eclosed workers in one colony also were not observed guarding, although they did sometimes emerge and forage.

A total of 87 episodes of entrance guarding, ranging in duration from 0.3 to 27 minutes, were recorded in 12 hours of observation of the two marked colonies. Typical behavioral sequences are depicted in Fig. 3. During diurnal observations (360 minutes), successions of individuals kept the nest entrance under guard for a total of 195.5 minutes, or $54 \%$ of the time (Table 1). At night, the number of episodes declined significantly (Table 1; Fig. 3, bottom), suggesting that this defense is primarily directed against a diurnal threat. A number of unusually long episodes were recorded at night, but mean duration did not change significantly. Though Brandao (1983) reported an increase in guarding in nests of $O$. affinis without queens, there was no significant difference between the number or duration of episodes in the queenright and queenless colonies (Table 1). In 15 cases, all during the day, an ant took up the guard posture behind another which already occupied the entrance (half-height bars in Fig. 3). Such "back-ups" were short (1.23 \pm 0.62 minutes, $\bar{x} \pm$ std. dev., with range $0.5-2.5$ ), and their frequency was significantly less than expected if guarding was independent of the presence of other guards (observed proportion $=0.172$, expected $=0.378, \mathrm{~N}=$ $87 ; p<0.0001$, binomial test). Since workers thus appeared to avoid acting as back-ups, these episodes were excluded from the analyses in Table 1.

All 19 workers in the queenless nest, and all but two of the 15 in the queenright one, participated in nest entrance guarding. There was some evidence of weak individual specialization in this behavior. The single individuals in each colony that were observed guarding most frequently (one worker in the queenright colony who guarded 10 times, while the others guarded no more than four, and one in the queenless colony who guarded seven times, the others no 

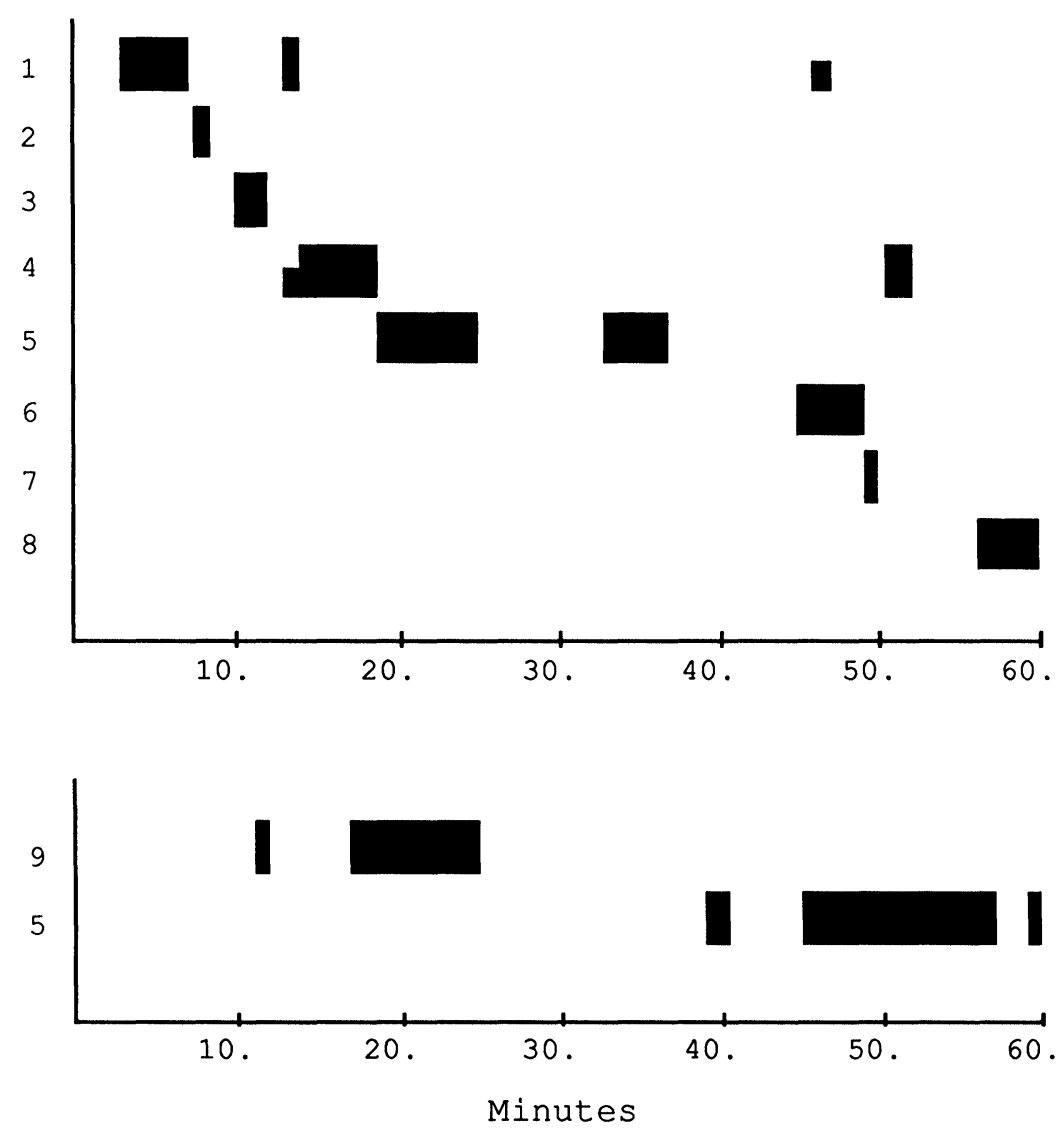

Fig. 3. Typical sequences of guarding behavior in a queenright $O$. ruginodis nest (two 1-hour observation sessions). Numbers indicate marked individuals. Full height bars indicate the duration of guarding episodes in the nest entrance; half-height bars indicate "back up" episodes, in which one individual took the guard posture behind another. Top: Diurnal session. Bottom: Nocturnal session.

more than five) together accounted for $37 \%$ of the total time the entrances were under guard in the two colonies (100 of 272 minutes), with the remaining $63 \%$ divided among the other 30 workers that guarded. These "specialists" stints in the entrance were not significantly longer than those of the other workers, however (Table 1). In the queenright colony the same individual, designated as number 5 in Fig. 3, was again noted guarding 27 days after the termination of 
the experiment, suggesting potential fidelity in the role over time. More pronounced specializations in other aspects of colony labor have been reported in O. troglodytes (Dejean and Nghuan 1987).

\section{Random model of the succession of nest guards}

The sequential succession of guarding episodes (seen as a diagonal pattern in Fig. 3, top) seems to suggest that the departure of one individual may somehow stimulate another to quickly replace her and keep the entrance under guard. However, this pattern can emerge from randomly distributed time intervals between episodes, according to a rather simple model in queueing theory. Assume that a new guard arrives at a random time following the end of the previous episode. For some probability $p$ that none will arrive in a given interval $t$, the probability that $n t$ time will elapse without a guard arriving is $p^{\mathrm{n}}$, which defines a negative exponential distribution with probability density function $(1 / \theta) \mathrm{e}^{-\mathrm{t} / \theta}$ (Lawless 1982). An exponential distribution of $\theta=4.779$ was fitted to the observed 43 non-zero intervals between episodes. (Seventy-two episodes in 12 observation periods yielded 60 inter-guarding intervals; 17 intervals

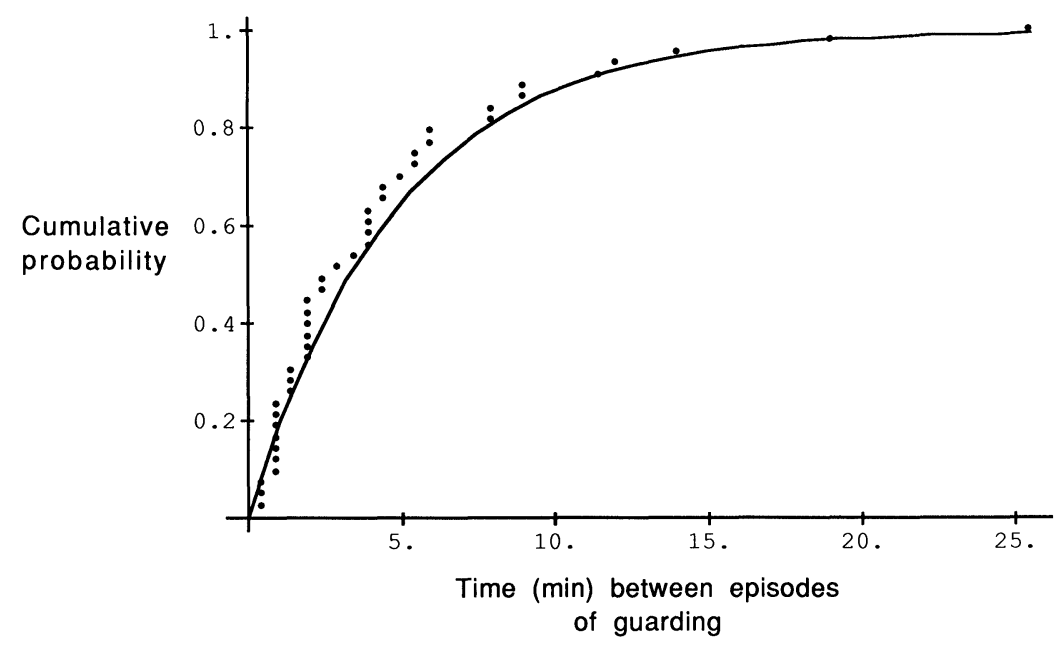

Fig. 4. Cumulative probability distribution of inter-guarding intervals (in minutes). Dots indicate observed times elapsed between guarding episodes $(\mathrm{N}=43)$; the sorted observations $x_{i}$ are plotted at position $\left(x_{i}, i / 43\right)$. Curve indicates a fitted negative exponential distribution, not significantly different from the observed data (see text). 
of 0 time were excluded because these occurred when a newlyarrived worker or a back-up displaced the current guard, thus representing truncated episodes rather than the process of replacement following a departure.) The observed distribution of interguarding intervals did not deviate significantly from the fitted distribution $\left(\chi^{2}=2.99,3\right.$ degrees of freedom, $p>0.05$; Fig. 4), consistent with the hypothesis that new workers initiate guarding randomly.

\section{Responses to intruders in the laboratory}

Alien ants entering the tube opening were rapidly ejected by mandibular snaps from the guard. Frame-by-frame playback of videotaped encounters revealed that the process consists of five stages (Fig. 5, left to right): (1) At rest in the entrance, the guard's mandibles are cocked and her antennae point forward. (2) If an intruder approaches, the guard extends her antennae toward it. (3) When the intruder is positioned between her antennal tips, she suddenly jerks forward. (4) A strike is set off by contact between her trigger hairs and the intruder's head (or other extremity, if the approach is at an angle), catching its tip between her mandibular teeth. (5) The apical teeth slide together along the hard convex surface, pinching with sufficient force to shoot the intruder backward, while the guard recoils. The forward lunge and strike ( 3 and 4 ) occur in less than $1 / 30$ th of a second. Strikes were never triggered by intruders blundering into the waiting mandibles. The guard always "sighted" with antennae before herself releasing the strike by jabbing the invader with her trigger hairs, which served as range finders. If an intruder walked between a guard's mandibles before she could eject it, she backed up and re-positioned it between her antennae before snapping.

When introduced into the entrance tube, workers of 12 ant species, including native and introduced sympatric species that are potential enemies or competitors of $O$. ruginodis and allopatric species of similar size, were repelled by bouncer guards (Table $2, \mathrm{~N}=$ 3-10 introductions per species). Aliens were frequently injured, as well as flung. Being struck was unlikely to incapacitate heavily sclerotized Tetramorium caespitum, or Pheidole dentata and $P$. megacephala major workers, though legs or antennae might be broken. However, the head capsules of Monomorium and Paratrechina spp. workers and Pheidole minors were often crushed. Since 

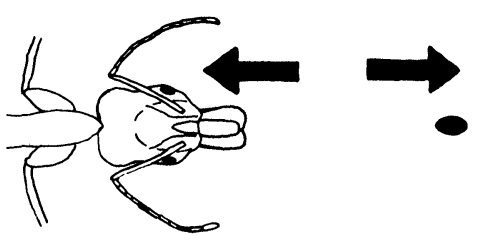

苟

.5

运

苟骂

8 s

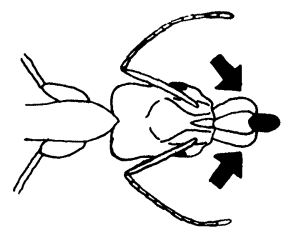

实

몁

范

昰

$0 \dot{0}$

ส
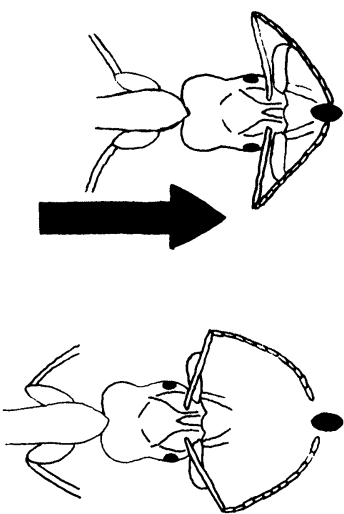

ลे

包

E

현

รี

पt 앙

응

등

ठ․

을

oᄋ

.

总

क

\&ิ

\%

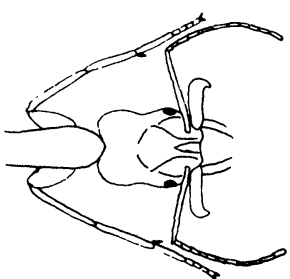

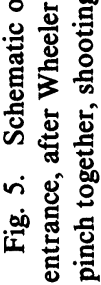


Table 2. Defensive responses of $O$. ruginodis workers to other ant species, staged in the nest entrance and in arenas. Sympatry with $O$. ruginodis in Florida and native or introduced status according to Deyrup et al. (1988).

Bounced (in nest entrance and arena):

Aphaenogaster rudis (allopatric)

Crematogaster minutissima (sympatric, native)

Cyphomyrmex minutus (sympatric, native)

Monomorium trageri (allopatric)

Paratrechina bourbonica (sympatric, introduced)

Paratrechina longicornis (sympatric, introduced)

Pheidole dentata (sympatric, native)

Pheidole megacephala (sympatric, introduced)

Solenopsis geminata (sympatric, native)

Solenopsis invicta (sympatric, introduced)

Tapinoma sessile (allopatric)

Tetramorium caespitum (allopatric)

Not bounced (in arena only):

Camponotus floridanus (sympatric, native)-limbs clipped off

Camponotus tortuganus (sympatric, native)-limbs clipped off

Pogonomyrmex badius (allopatric)-limbs clipped off

Conspecifics from other colonies-limbs clipped off, stung

intruders were introduced into the entrance tube in confining vials, to determine how far ants could be flung in the absence of obstructions, encounters were videotaped in open arenas and subsequently measured. In 50 successful strikes at $T$. caespitum workers, the mean distance travelled by the aliens was $4.05 \pm 3.07 \mathrm{~cm}(\overline{\mathrm{x}} \pm \mathrm{std}$. dev.), with a range of $1.2-14 \mathrm{~cm}$. This range represents roughly 4 to 45 times the length of a $T$. caespitum worker (approximately $3 \mathrm{~mm}$ ), which presumably constitutes an effective displacement for small ants. Most of the sympatric species in Table 2 are comparable in size.

Three species which are larger than $O$. ruginodis (Camponotus floridanus, C. tortuganus and Pogonomyrmex badius) were introduced only in arenas (Table 2). These ants were repeatedly struck but not flung backward; instead, their limbs and antennae were rapidly clipped off. In encounters between $O$. ruginodis workers from different colonies, some were dismembered in the same manner, while others were seized in the mandibles and stung. $O$. ruginodis workers never used the sting on any other ant species, 
though they did sting a vertebrate (one of the authors) and certain types of prey (ant larvae and pieces of cockroach). Nasutitermes and Reticulitermes workers were struck with the mandibles but not stung, consistent with the report by Dejean and Bashingwa (1985) that $O$. troglodytes workers sometimes sting large termite prey, but always kill small termites with mandibular strikes.

Responses to intruders by workers of three other Odontomachus species, $O$. bauri, $O$. brunneus and $O$. clarus, were tested in nest entrance tubes or arenas. These ants snapped at approaching aliens (Pheidole, Solenopsis and Tetramorium spp.) and flung them backward in the same fashion. One T. caespitum worker flew for a distance of over $15 \mathrm{~cm}$ after being struck by an $O$. bauri worker, and had not reached the ground when it hit the arena wall. Another large $O$. bauri worker succeeded in shooting a Pogonomyrmex badius worker for a short distance. Workers of Anochetus emarginatus confronted with Aphaenogaster rudis also shot them away with mandibular strikes.

\section{Ablation experiments}

The sensory mechanisms involved in releasing the mandibular snap were investigated experimentally by depriving $O$. bauri workers of various modalities and observing arena interactions with Aphaenogaster rudis workers (Table 3). The so-called trigger hairs proved not to be essential, as apparently normal and effective mandibular snaps could be executed after they were removed (treatment 1, Table 3). Removal of one or both antennae (treatments 2 and 3) or the hairs and both antennae (4) also had no effect on the response. Though ants with both antennae ablated became relatively inactive, they still followed approaching aliens with head movements suggesting visual tracking, and struck successfully at those that came close. Workers whose eyes were painted over, but otherwise intact (5), appeared unable to use antennae alone to orient toward aliens from a distance, but did accurately strike at those they contacted accidentally. With eyes occluded and either hairs or antennae removed (6 and 7), workers continued to strike at aliens they contacted, but frequently missed. If all three modalities were ablated (8), aiming at the target was not possible, though some undirected snaps were provoked by aliens that seized the operated workers' legs. 
Table 3. Mandibular snaps by $O$. bauri workers in ablation experiments, described in text. +: intact; - : ablated. $\mathrm{N}=2$ workers per treatment, except for treatment 8 , in which $\mathrm{N}=6$ workers.

\begin{tabular}{ccccc}
\hline Treatment & Trigger Hairs & Antennae & Eyes & Snap? \\
\hline Untreated & + & + & + & Yes \\
1 & - & + & + & Yes \\
2 & + & - & + & Yes \\
3 & + & - & + & Yes \\
4 & - & + & + & Yes \\
5 & + & - & - & Yes \\
6 & + & + & - & Poorly \\
7 & - & - & - & Poorly \\
8 & - & & - & No \\
\hline
\end{tabular}

\section{Discussion}

The bouncer defense, as described in a laboratory study of the dacetine ant Orectognathus versicolor (Carlin 1981), is comprised of two components, guarding the nest entrance and using the mandibular strike to shoot would-be invaders away. We observed both of these behaviors in Odontomachus ruginodis colonies in the field and laboratory. Thus the trap-jaw mechanism, a predatory adaptation which originated convergently in three independent ant subfamilies (the Dacetini, Odontomachini and Myrmoteratini), has been secondarily co-opted for defense at least twice. This is not perhaps surprising, given that guarding is not a very complex behavior; evidence suggests only weak individual specialization, and the succession of guards fits a random model from queueing theory. The bouncer defense would require little evolutionary innovation, and in this context the trap jaws presumably provide the same considerable advantage hypothesized by Brown (1976) for the capture of wellarmed prey: minimizing contact with the opponent. Small, wellsclerotized intruders may be displaced by many times their length, effectively preventing them from entering the nest. Such a low-risk method of deterring invaders could be quite important to ants whose modified mandibles are less effective in conventional grappling fights, and whose relatively small colonies can ill afford the loss of many workers.

Intruders ejected by $O$. ruginodis guards often also lost limbs or antennae, if those parts were caught between the sharp apical teeth. 
By contrast, Orectognathus versicolor majors, whose apical teeth are very robust, peg-like and blunt, usually bounce their opponents intact. The majors rarely capture prey and do little besides stand in the nest entrance or around the queen ready to strike, while the minors, whose teeth are more slender and sharp, carry out most colony activities including predation (Carlin 1981). In this species, the only polymorphic member of its genus (and one of few polymorphic dacetines), the behavioral co-option of the predatory strike for defense appears to have been followed by morphological specialization, enhancing pinching ability at the expense of prey capture and more general functionality. The majors' trap jaws and adductor muscles are so well adapted to this role that one can shoot a small intruder for a distance of up to $9 \mathrm{~cm}$, nearly as far as can an Odontomachus ruginodis worker, though the former is little longer than the latter's head. In monomorphic odontomachines, mandible form is constrained by the need not only to capture prey, but also to handle brood, excavate nests, etc., and the bouncer defense is limited to an alteration in behavior and not morphology.

Opponents too large to be flung were dismembered with repeated mandibular strikes, reducing them to helpless torsos as vividly described in Wheeler's (1900) account of attacks by Odontomachus clarus workers on species of comparable size. The use of the sting only on conspecifics, not on other ant species, was surprising, particularly since several members of the genus have been observed to accept alien conspecifics without hostility (O. clarus (Wheeler 1900), O. troglodytes (Colombel 1970), O. affinis (Brandao 1983); but see Jaffe and Marcuse (1983), who recorded aggression and occasional stinging between $O$. bauri colonies). We noted that, although foreigners were always discriminated against, attacks declined in intensity after colonies had been maintained in the laboratory for long periods, suggesting a possible environmental contribution to nestmate recognition as reported in some other ant species (Obin 1986, Stuart 1987).

Bouncing was also observed in workers of several other Odontomachus species and of Anochetus emarginatus, despite the absence in the latter genus of shelf-like muscle attachments in the posterior vertex, which may make the mandibular strike more effective in Odontomachus (Brown 1976). It therefore seems probable that the behavior is widely distributed throughout the Odontomachini. The 
two dacetines known to exhibit this response, Orectognathus versicolor and Daceton armigerum (Carlin 1981 and unpublished observations), both belong to primitive genera within their tribe (Brown and Wilson 1959), and it would be interesting to examine the defense behavior of other genera, many of which have reduced mandibles. The formicine Myrmoteratini have have rather more slender, delicate mandibles, with less well developed apical teeth than most members of the other two tribes, and in this group the bouncer defense is probably not an effective option. These ants have a different method of attacking enemies at arms' length, by beating them with repeated mandibular strikes. The mandibles riccochet off a hard-bodied intruder, but it usually flees (Moffett 1986).

The results of ablation experiments contradicted previous suggestions that the snapping of trap-jaws is a simple sensorimotor reflex released by the stimulation of "trigger" hairs (e.g., Wheeler 1900). Instead, multiple modalities provide redundant information for first localizing an approaching object, and then orienting the strike. In Odontomachus bauri, visual input appears to be required for initial fixation, after which vision plus either the antennae or trigger hairs may be used to aim. The absence of trigger hairs defines one of the two subgenera of Myrmoteras distinguished by Moffett (1985), who speculated that the hairs are a derived feature related to specialization on collembolan prey (Moffett 1986). The exceptionally large eyes of these ants suggest that they too can probably orient quite adequately by vision alone. Some Strumigenys species also lack trigger hairs (Creighton 1930), and ablation experiments with soldiers of Daceton armigerum show that vision can suffice for effective mandibular strikes in a dacetine (Carlin, unpublished observations).

\section{ACKNOWLEDGMENTS}

We are grateful to William Spencer for recording nest guarding data, Eva Yablonsky and Thomas Graham for maintenance of laboratory colonies, Prassede Calabi, Marty Fujita, Carlos Garcia, Stephen Pratt and Diana Wheeler for collecting ants, and Mark Deyrup and Stefan Cover for identifying them. We also thank Ed Seling for the electron photomicrographs, Bert Hölldobler for the photograph in figure 2, Marcie Terman for assistance with video equipment, and Prassede Calabi, Stefan Cover and Bert Hölldobler 
for comments on the manuscript. Supported by N.S.F. grant BNS 82-19060 to B. Hölldobler and Harvard University Richmond Fund grants to N. F. Carlin.

\section{REFERENCES}

BARTH, R.

1960. Über den Bewegungsmechanismus der Mandibeln von Odontomachus chelifer Latr. (Hymenopt., Formicidae). An. Acad. Brasil. de Ciencias, 32: 379-384.

Bhatkar, A. AND W. H. Whitcomb

1970. Artificial diet for rearing various species of ants. Fla. Entomol., 53: 229-323.

BrandaO, C. R. F.

1983. Sequential ethograms along colony development of Odontomachus affinis Guerin (Hymenoptera, Formicidae, Ponerinae). Insect. Soc., 30: 193-203.

Brown, W. L., JR.

1976. Contributions toward a reclassification of the Formicidae. Part VI. Ponerinae, tribe Ponerini, subtribe Odontomachini. Section A. Introduction, subtribal characters. Genus Odontomachus. Stud. Entomol., 19: $67-171$.

AND E. O. WILSON

1959. The evolution of the dacetine ants. Quart. Rev. Biol., 34: 278-294.

Carlin, N. F.

1981. Polymorphism and division of labor in the dacetine ant. Orectognathus versicolor. Psyche, 88: 231-244.

Colombel, $\mathrm{P}$.

1970. Recherches sur la biologie et l'ethologie d'Odontomachus haematodes L. (Hym., Formicoidea, Poneridae). Insect. Soc., 17: 183-204.

Creighton, W. S.

1930. A review of the genus Myrmoteras (Hymenoptera: Formicidae). J. New York Ent. Soc., 38: 177-193.

DeJEAn, A.

1986. Etude du comportement de predation dans le genre Strumigenys (Formicidae-Myrmicinae). Insect. Soc., 33: 388-405.

AND E. BASHINGWA

1985. La predation chez Odontomachus troglodytes Santschi (FormicidaePonerinae). Insect. Soc., 32: 23-42.

AND O. A. NGHuan

1987. Contribution to the study of polyethism of Odontomachus troglodytes (Formicidae, Ponerinae). In Chemistry and Biology of Social Insects, J. Eder and H. Rembold, eds. J. Peperny Verlag, Munich, pp. 455-458.

Deyrup, M., N. F. Carlin, J. Trager and G. Umphrey

1988. A review of the ants of the Florida Keys. Fla. Entomol., 71: 163-175. 
J. Trager and N. F. Carlin

1985. The genus Odontomachus (Hymenoptera: Formicidae) in the southeastern United States. Entomol. News, 95: 188-195.

FOWLER, H. G.

1980. Populations, prey capture and sharing, and foraging of the Paraguayan ponerine Odontomachus chelifer Latrielle. J. Nat. Hist., 14: 79-84.

HölLDobler, B. AND E. O. WilsoN

In press. The ants. Harvard University Press, Cambridge, MA.

JAFFE, K. AND M. MARCUSE

1983. Nestmate recognition and territorial behavior in Odontomachus bauri Emery (Formicidae: Ponerine). Insect. Soc., 30: 466-481.

LAWLESS, J. F.

1982. Statistical models and methods for lifetime data. John Wiley and Sons, NY.

LEDOUX, A.

1952. Recherches preliminaires sur quelques points de la biologie d'Odontomachus assiniensis Latr. (Hym. Formicoidea). Ann. Sc. Nat. Zool., 11: 231-248.

MOFFETT, M. W.

1985. Revision of the genus Myrmoteras (Hymenoptera: Formicidae). Bull. Mus. Comp. Zool., 151: 1-51.

1986. Trap-jaw predation and other observations on two species of Myrmoteras (Hymenoptera: Formicidae). Insect. Soc., 33: 85-99.

OBIN, M.

1986. Nestmate recognition cues in laboratory and field colonies of Solenopsis invicta Buren (Hymenoptera: Formicidae): effect of environment and the role of cuticular hydrocarbons. J. Chem. Ecol., 12: 1965-1975.

STUART, R. J.

1987. Transient nestmate recognition cues contribute to a multicolonial population structure in the ant, Leptothorax curvispinosus. Behav. Ecol. Sociobiol., 21: 229-235.

WASSMANN, E.

1892. Einiges über springende Ameisen. Wiener Entomol. Zeitschr., 11: 23-24.

WEYER, F.

1930. Über das "Springen" von Odontomachus. Zool. Anz., 90: 49-55.

WHEELER, J. W. AND M. S. BLUM

1973. Alkylpyrazine alarm pheromones in ponerine ants. Science, 182: 501-503.

WHEELER, W. $\mathrm{M}$.

1900. A study of some Texan Ponerinae. Biol. Bull., 2: 1-31.

1922. Observations on Gigantiops destructor Fabricius and other leaping ants. Biol. Bull., 42: 185-201.

1927. The physiognomy of insects. Quart. Rev. Biol., 2: 1-36. WILSON, E. O.

1962. Behaviour of Daceton armigerum (Latr.) with a classification of selfgrooming movements in ants. Bull. Mus. Comp. Zool., 127: 403-422. 

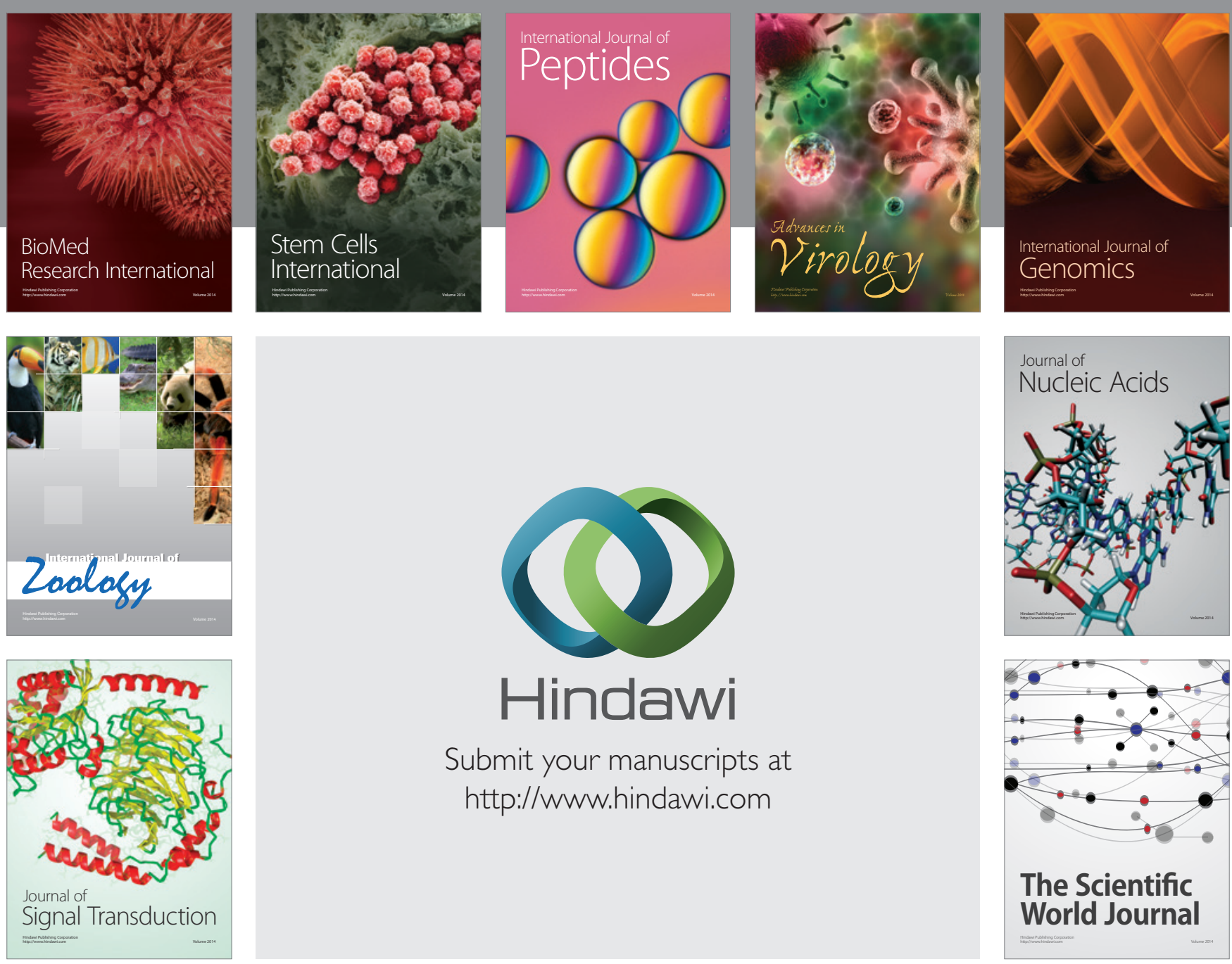

Submit your manuscripts at

http://www.hindawi.com
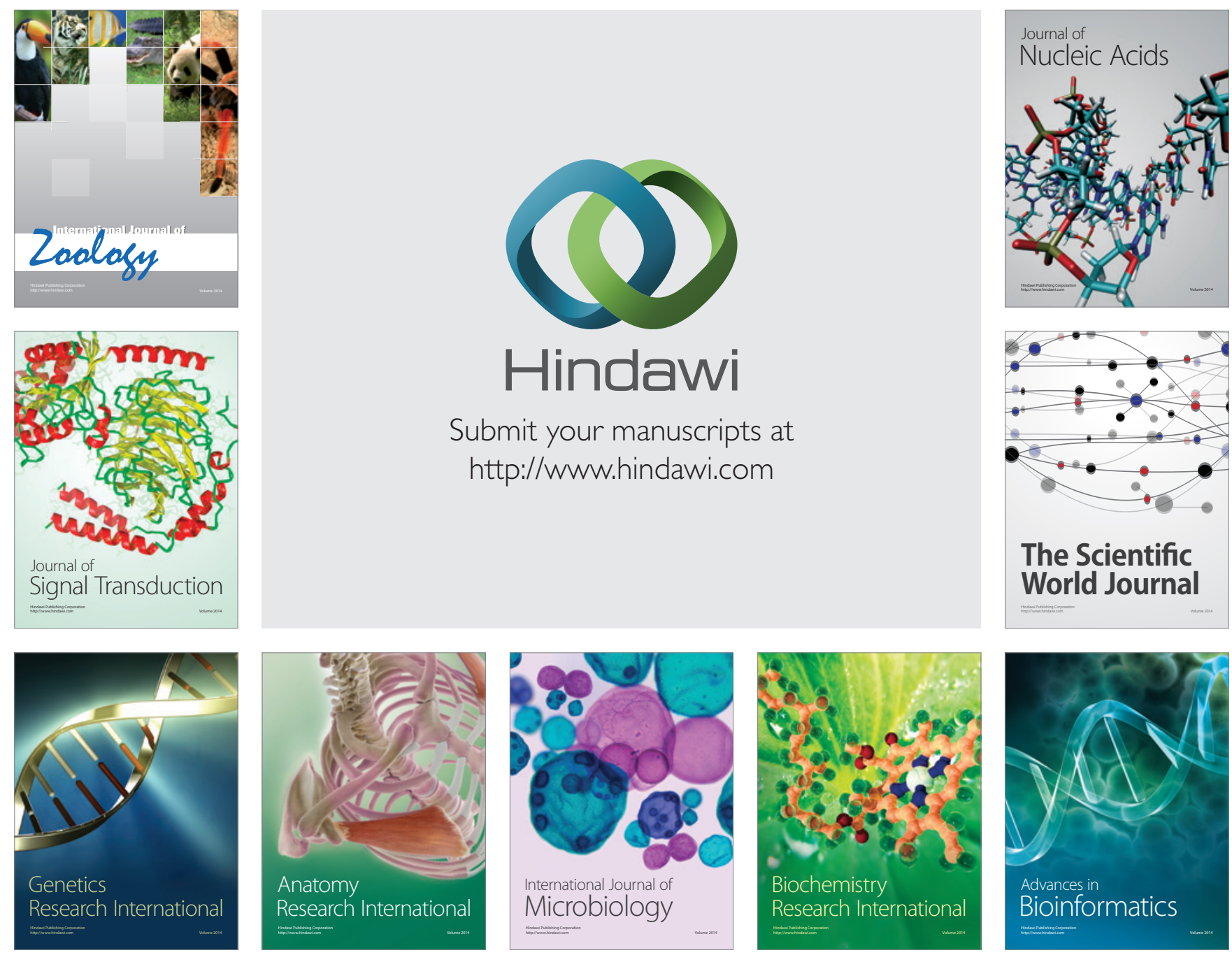

The Scientific World Journal
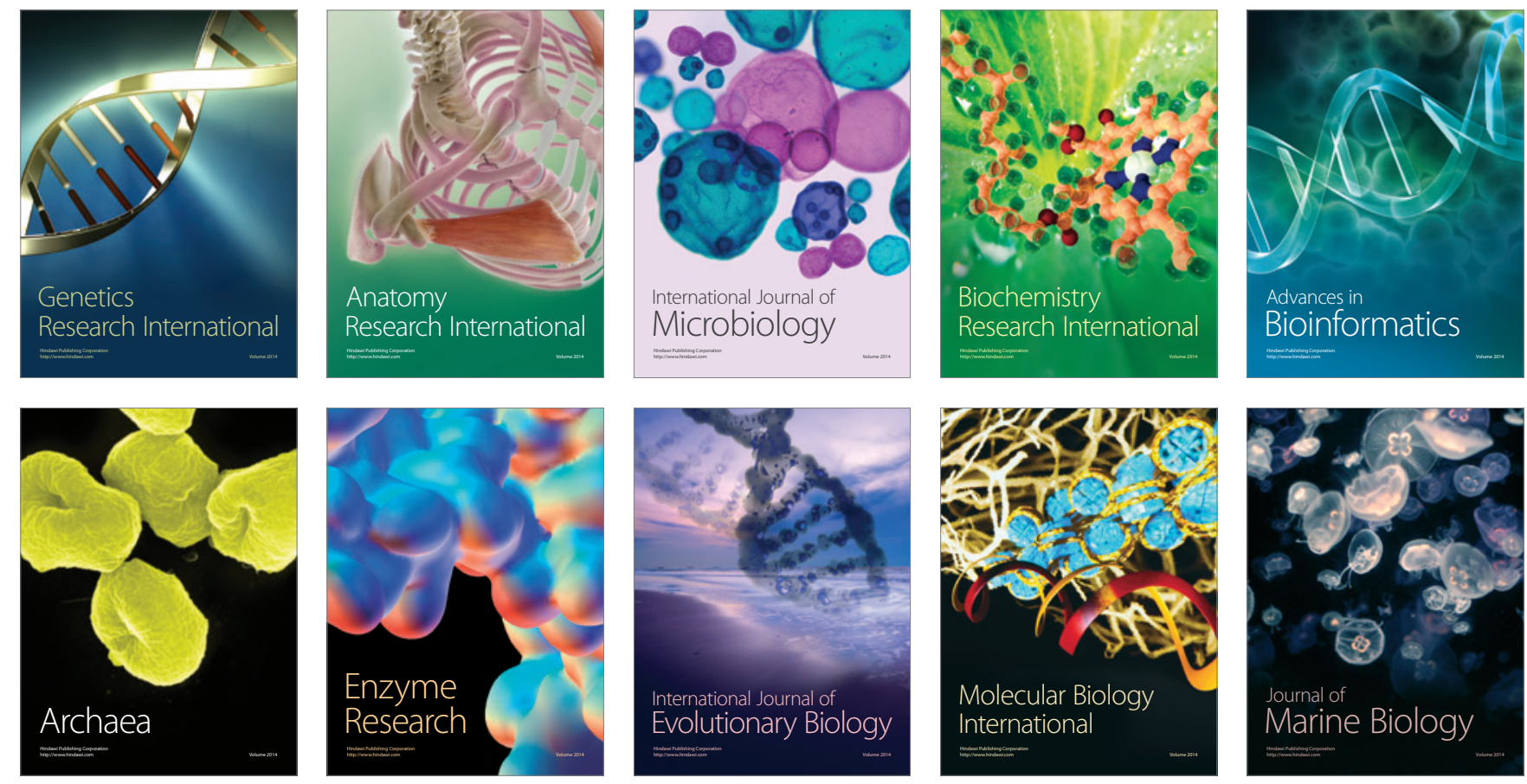